\title{
Resilience of Regional Transportation Networks Subjected to Hazard-Induced Bridge Damages
}

\author{
Richard Twumasi-Boakye, A.M.ASCE${ }^{1}$; and John O. Sobanjo, Ph.D., P.E., F.ASCE ${ }^{2}$
}

\begin{abstract}
The comprehension of network-level consequences resulting from disruptive events is a main gray area in the evaluation of transportation network resilience at the regional level. Explaining hazard impacts on regional network infrastructures and identifying significantly affected areas are important for communicating the need for building resilient infrastructure. This paper presents a framework for assessing the regional network resilience by leveraging scenario-based traffic modeling and GIS techniques. High-impact-zone location identification metrics were developed and implemented in preliminarily identifying areas affected by bridge closures. Resilience was estimated, and an index developed by utilizing practical functionality metrics based on vehicle distance and hours traveled. These are illustrated for the Tampa Bay, Florida, area. Findings for 10 bridge closure scenarios and recovery schemas indicated significant regional resilience losses. The I-275 bridge closure indicated the highest functional loss to the regional network: the aggregated resilience index below 0.5 reflects severe network performance deficit and mobility limitations. DOI: 10.1061/JTEPBS.0000186. @ 2018 American Society of Civil Engineers.
\end{abstract}

Author keywords: Resilience; Transportation network; Bridge closures; Network performance.

\section{Introduction}

Lifeline systems have been of growing concern, especially considering their vulnerability to hazard-induced damages. Findings from previous studies mention transportation infrastructure as one of the most vital lifeline systems (Hopkins et al. 1993). Extreme natural events such as hurricanes, tornadoes, earthquakes, and wildfires, as well as intentional hazards are threats to critical infrastructure systems including transportation networks. The locations of bridges, an integral part of the transportation network configuration, indicate that they are critical to mobility. Bridges that serve as cross-terrain and cross-waterbody structures play a major role in minimizing travel costs. Structural and functional losses to such bridges often lead to mobility limitations and increased user costs (Twumasi-Boakye and Sobanjo 2017). For this reason, it is imperative that they are made more robust. Effective measures are also needed to facilitate rapid postdisaster recovery. Therefore, it is necessary to establish an efficient approach to pre-event evaluation of transportation infrastructure.

The traditionally acknowledged concept for evaluating the ability of infrastructure to resist the effects of hazards and recover quickly is termed resilience. Resilience evaluates a system's ability to resist and absorb the impacts of disruptions (Bruneau et al. 2003) by building on the strengths or weaknesses measured by other indicators such as reliability, robustness, risk, and vulnerability (Faturechi and Miller-Hooks 2014a). In this paper, the definition

\footnotetext{
${ }^{1}$ Graduate Research Assistant, Dept. of Civil and Environmental Engineering, Florida State Univ., A129, 2525 Pottsdamer St., Tallahassee, FL 32310-6046 (corresponding author). Email: rt12f@my.fsu.edu

${ }^{2}$ Professor, Dept. of Civil and Environmental Engineering, Florida State Univ., A129, 2525 Pottsdamer St., Tallahassee, FL 32310-6046. Email: jsobanjo@fsu.edu

Note. This manuscript was submitted on September 13, 2017; approved on May 9, 2018; published online on August 13, 2018. Discussion period open until January 13, 2019; separate discussions must be submitted for individual papers. This paper is part of the Journal of Transportation Engineering, Part A: Systems, (C) ASCE, ISSN 2473-2907.
}

of resilience was applied to regional transportation networks by explaining regional network resilience as the ability of regional transportation networks to minimize functional losses due to major components breakdown and recover rapidly to predisruption conditions.

Many studies over the last decade have addressed resilience assessment methods for infrastructure systems. Previous efforts to quantify the resilience of transportation networks include studies by Murray-Tuite (2006) and Zhang et al. (2009). Murray-Tuite (2006) proposed adaptability, safety, mobility, and recovery as four dimensions of resilience, and highlighted indicators such as multimodality, incident occurrence, evacuation time, interzonal travel time, and level of service. Bocchini and Frangopol (2010) used total travel time (TTT) and total travel distance (TTD) for resilience evaluation by considering multiple bridge configurations in the proposed resilience assessment concept. Bocchini et al. (2013) in a study on bridge network restoration after earthquake events developed a multicriteria intervention optimization approach that was exemplified on a large network.

A thorough review of the respective literature shows that while most studies excel in the identification and development of relevant resilience metrics, few studies focus on the development of single-measure indicators (index) for resilience. Pertinent studies that report on resilience index formulation include efforts by Attoh-Okine et al. (2009) and Serulle et al. (2011). Other researches have taken the form of qualitative concepts (Vugrin et al. 2011; Tamvakis and Xenidis 2012; Hughes and Healy 2014) as well as quantitative frameworks (Cox et al. 2011; Omer et al. 2011; Reggiani 2013; Adjetey-Bahun et al. 2016; Gillen and Hasheminia 2016; Karamlou et al. 2016; Donovan and Work 2017). Application of resilience metrics to realistic networks, especially regional transportation models, is lacking in the literature. Developed metrics applied to test networks are mostly based on assumptions specific to those sample networks. Additionally, high-impact-zone location metrics important for identifying jurisdictions that need immediate attention during hazard events are yet to be developed. 


\section{Background}

Florida has recorded more major hurricanes (37) than any other US state between 1851 and 2010 (Blake et al. 2007). An extensive study by Sobanjo and Thompson (2013) evaluated the risks to which Florida bridges are exposed, attributable to both natural and anthropogenic hazards. Hazards such as hurricanes, tornadoes, flooding and scour, and wildfires were investigated. Hurricanes were identified as a main cause of bridge damage among natural hazards, with coastal bridges being of primary concern.

Reports on Hurricane Katrina revealed that the mixture of winds, rains, and storm surges resulted in severe damage to coastal bridges. Substantial amounts of these damages were reported as the displacement of bridge decks and the collapse of facilities for movable bridges (Padgett et al. 2008). Vulnerability of coastal bridges to hurricanes (Padgett et al. 2012) and their corresponding consequences (Stearns and Padgett 2011) in the form of agency costs have further been evaluated (Maxey 2006).

Unexpected closures to major bridges have been reported to cause widespread traffic disruptions. Thus, it is necessary to study the impacts of such closures on large transportation networks. On September 16, 2004, storm surges and waves resulting from Hurricane Ivan had massive consequences on I-10 bridges over Escambia Bay causing the displacement of several bridge spans as well as complete pier removal (Hitchcock et al. 2008). A period of 66 days after the hurricane event was needed to reconstruct and reopen the Escambia Bay Bridge to traffic (Hitchcock et al. 2008). The loss of this bridge resulted in an approximately $209-\mathrm{km}$ (130-mi) traffic detour (Talbot 2005), implying increased transportation user costs. The importance of bridges as lifelines cannot be overstated. A section of the I- 85 bridge in Atlanta collapsed after a massive fire (12.19-m wall of fire) on March 20, 2017. Three sections of I-85 northbound and southbound required replacement and it took more than 6 weeks to reopen the southbound lanes of the bridge to traffic (Burns and Brett 2017). The estimated daily vehicular traffic on this Atlanta roadway section was 220,000 vehicles per day. Due to this high traffic volume, the bridge closure resulted in traffic on the I-285 bypass increasing by $50 \%$ the following day due to traffic gridlock, with traffic conditions in the Atlanta area substantially affected (Noll 2017).

A methodological framework for predisaster resilience evaluation of realistic regional networks based on hypothetical postevent damage state conditions is essential to mitigate the effects of unexpected closures.

\section{Scope of Study}

The National Infrastructure Advisory Council (NIAC) indicated that deficit in the comprehension of network-level consequences resulting from major disruptive events is one of the main gray areas in the transportation network resilience discussion (Baylis et al. 2015). This study seeks to contribute to the ongoing debate on transportation network resilience by presenting preliminary efforts to quantify resilience at the network or regional level.

The primary focus of this paper is to determine transportation network resilience for regional models based on bridge closures. Essentially, this work takes into account the network-level damage to bridges and the resulting impacts on regional road network jurisdictions. While current methods focus on the best alternative routes during bridge closures, it is important to comprehend that the resulting impacts of such disruptions are extensive and have widespread effects. In this study, even though bridge closure scenarios and durations of closures were considered, specific interest was in the resilience of the transportation network system. Assessing transportation networks through scenario-based modeling is the suggested approach. Such techniques can help researchers and agencies to answer questions regarding the consequences of road closures resulting from disruptive events. Furthermore, this paper identifies and quantifies practical indicators for evaluating transportation network resilience. A metric for identifying high-impact zones for regional networks during disruptions was also developed in this work. Finally, an aggregated network resilience index measure was developed as a single-value indicator of the level of resilience in an existing transportation network.

\section{Methodology}

With the aim of developing an aggregated resilience index (ARI) measure, the following methodological steps were undertaken: (1) establishing the transportation network and adopting the concept of an equilibrium-based traffic assignment; (2) identifying practical transportation network performance metrics and indicators; (3) identifying high-impact-zone location metrics; (4) developing a computational approach for measuring functionality; (5) adopting the proposed resilience triangle method (Bruneau et al. 2003) for computing a single resilience index; and (6) computing an aggregated resilience index from individual indexes. The highlighted steps were integrated to obtain an aggregated resilience index: traffic flow results from the equilibrium-based traffic assignment were utilized for computing measures of performance. A highimpact-zone metric developed in this study was utilized to preliminarily identify network segments with high speed differences resulting from closures. The performance measures from traffic assignment outputs were then used for computing the network functionality; the aggregated resilience index was estimated as the mean resilience (function of network functionality and recovery time) index based on identified metrics. These steps are succinctly discussed in the following subsections.

\section{Equilibrium-Based Traffic Assignment}

Transportation demand models are usually structured around four sequential steps commonly referred to as the Four-Step Modeling Process: trip generation, trip distribution, mode choice, and trip assignment. In order to compute the link travel costs for the transportation network, a user equilibrium assignment was used in the traffic assignment model for this study. The user equilibrium assignment was based on Wardrop's first principle, which stipulates that no user can lower transportation cost unilaterally by changing routes (Daskin and Sheffi 1985). This further implies that with drivers having a perfect knowledge of network travel costs, they are prone to choosing the best routes, leading to a deterministic user equilibrium formulated as a nonlinear mathematical optimization program (Daskin and Sheffi 1985) as

$$
\begin{aligned}
& \text { minimize } S=\sum_{q} \int_{0}^{x_{q}} t_{q}\left(x_{q}\right) d x \\
& \text { Subject to } \sum_{k} f_{k}^{u v}=q_{u v}: \forall u, v \\
& x_{q}=\sum_{u} \sum_{v} \sum_{k} \delta_{q, k}^{u v} f_{k}^{u v}: \forall q \\
& f_{k}^{u v} \geq 0: \forall k, u, v \\
& x_{q} \geq 0: q \in Q
\end{aligned}
$$


where $S=$ objective function; $k=$ path; $x_{q}=$ equilibrium flows in link $q ; t_{q}=$ travel time on link $q ; f_{k}^{u v}=$ flow on path $k$ connecting origin-destination (O-D) pair $u-v ; q_{u v}=$ trip rate between $u$ and $v ; Q=$ set of all links in the network; and $\delta_{q, k}^{u v}=$ definitional constraint ( 1 if link $q$ belongs to path $k, 0$ otherwise).

In this study, the link congestion performance function formulated by the Bureau of Public Roads (BPR) was used to determine the average travel time for each link (Transportation Research Board 1985). The equation is as follows:

$$
t_{q}\left(x_{q}\right)=f t_{q}\left(1+\alpha\left(x_{q} / c_{q}\right)^{\beta}\right)
$$

where $f t_{q}=$ free flow travel time (FFTT) on link $q$ per unit time; $x_{q}=$ volume of vehicles attempting to use link $q ; c_{q}=$ capacity on link $q$; $t_{q}\left(x_{q}\right)=$ average travel time for vehicle on link $q$; $\alpha=$ alpha coefficient, which is assigned a value of 0.15 in the original BPR curve; and $\beta=$ beta coefficient, the exponent of the power function, which is assigned a value of 4 in the original BPR curve.

\section{Practical Metrics and Performance Indicators}

\section{Measure of Vehicle Distance Traveled}

The approach of using vehicle distance traveled (VDT) and vehicle hours traveled (VHT) for computing transportation network performance was adopted from Dalziell and Nicholson (2001), who used similar metrics in estimating the risk and impact of natural hazards on a road network. These metrics have also been applied in vulnerability (Tanasić et al. 2013) and optimal resilience studies (Bocchini and Frangopol 2010). In this paper, VDT indicates the total vehicle travel distance and was computed for each link pair in the transportation network as the product of link traffic volume and link distance. Increase in link VDT from the uninterrupted network highlights functional loss or increase in travel costs. For each closure scenario, VDT can be computed as

$$
\begin{gathered}
\operatorname{VDT}(s)=\sum_{i \neq j} \operatorname{VDT}_{i j}(s) \\
\operatorname{VDT}_{i j}(s)=v_{i j} d_{i j}(s)
\end{gathered}
$$

where $\mathrm{VDT}_{i j}=$ vehicle distance traveled between nodes $i$ and $j$; $v_{i j}=$ volume of vehicles between nodes $i$ and $j$; and $d_{i j}=$ link distance between nodes $i$ and $j(\mathrm{~km})$.

\section{Measure of Vehicle Hours Traveled}

Travel time is well known as an important measure of mobility (Murray-Tuite 2006) and has been identified as a practical measure for determining resilience of transportation networks (Omer et al. 2013; Faturechi and Miller-Hooks 2014b). VHT is computed for each travel path as the product of traffic volume and travel time. This metric is essential since it reflects delay in travel. This can be estimated using the following equations:

$$
\begin{gathered}
\operatorname{VHT}(s)=\sum_{i \neq j} \operatorname{VHT}_{i j}(s) \\
\operatorname{VHT}_{i j}(s)=v_{i j} t_{i j}(s)
\end{gathered}
$$

where $\mathrm{VHT}_{i j}=$ vehicle hours traveled between nodes $i$ and $j ; v_{i j}=$ volume of vehicles between nodes $i$ and $j$; and $t_{i j}=$ link congested travel time (CTT) between nodes $i$ and $j(\mathrm{~h})$.

\section{High-Impact-Zone Location Metric}

Hazard-induced damages usually have widespread effects. However, in order to determine the resulting impact on transportation networks, it is imperative to identify specific locations where traffic gridlocks mostly occur. Already discussed metrics such as VDT and VHT are beneficial in quantifying performance and resilience, while metrics such as link travel time and link speeds aid in the identification of high-impact areas. The differences in predisaster to postdisaster link speeds are represented spatially using GIS mapping techniques. This serves as an effective method for locating areas of significant speed reduction, or high-impact zones. In this paper, a measure for percentage reduction in link speed was computed as the mean percentage difference between link speeds for the base (no closure) and bridge damage traffic assignment scenarios.

Furthermore, in an attempt to determine which links were most affected by the shock event, link speed reductions greater than or equal to $1.61 \mathrm{~km} / \mathrm{h}(1 \mathrm{mi} / \mathrm{h}), 4.83 \mathrm{~km} / \mathrm{h}(3 \mathrm{mi} / \mathrm{h})$, and $8.05 \mathrm{~km} / \mathrm{h}$ $(5 \mathrm{mi} / \mathrm{h})$ were used for identifying significantly affected links. While fallen sign structures, debris, and inoperable traffic signals from hurricane events may cause reduced link speeds, these are mostly resolved more rapidly than damaged bridges (Xie et al. 2015). Bridge closures may cause long-term closures resulting in sustained reduced speeds and gridlock on segments of regional networks if not addressed promptly. For real-time roadway conditions, however, other events unrelated to hazards (even immediately after hazard events) may cause congestion and therefore result in reduced link speeds; nevertheless, impacts may be more localized than regional. This study takes into account only hazard-induced bridge closures. The traffic assignment model therefore optimally reassigns traffic on routes to account for closures. Reductions in link metrics were therefore solely due to the bridge closure scenarios. Second, since the model was a static assignment model, each model rerun provided the same results per scenario.

Reductions in posted speed limits from 48.28 to $40.23 \mathrm{~km} / \mathrm{h}$ (30 to $25 \mathrm{mi} / \mathrm{h}$ ) have been reported to cause about $1.61-\mathrm{km} / \mathrm{h}$ (1-mi/h) reduction in actual vehicle speeds (Scott and Maddox 2001). This speed reduction reduces vehicle collision by $5 \%$ (Scott and Maddox 2001). Therefore, network link pairs showing marginal postdisaster speed reductions can serve as indicators for preliminarily identifying adversely impacted roadways due to major bridge closures on the regional network. The average link speed of $1.61 \mathrm{~km} / \mathrm{h}(1 \mathrm{mi} / \mathrm{h})$ suggests the posted speed would be reduced by approximately $8.05 \mathrm{~km} / \mathrm{h}(5 \mathrm{mi} / \mathrm{h})$. The choice of an $8.05-\mathrm{km} / \mathrm{h}(5-\mathrm{mi} / \mathrm{h})$ reduction in the average link speed was to serve as an upper limit, emphasizing links that were most affected by closures. The mean of 1.61 and $8.05 \mathrm{~km} / \mathrm{h}(1$ and $5 \mathrm{mi} / \mathrm{h})$ was chosen as $4.8 \mathrm{~km} / \mathrm{h}(3 \mathrm{mi} / \mathrm{h})$ to serve as an intermediary between the upper and lower limits. This metric is relevant to agencies in terms of hazard response since such events require effective operational measures to enhance mobility in affected areas.

This measure was computed as

$$
\begin{aligned}
\omega= & \frac{\sum_{q=1}^{n}\left\{\left(\frac{S_{R q}-S_{B q}}{S_{B q}}\right) \times 100\right\}}{n}, \\
& \forall q \in Q, Q:\left|\left(S_{R}-S_{B}\right)\right| \geq 1.61,4.83, \\
& \text { or } 8.05 \mathrm{~km} / \mathrm{h}(1,3, \text { or } 5 \mathrm{mi} / \mathrm{h})
\end{aligned}
$$

where $\omega=$ high-impact-zone metric; $S_{R q}=$ speed on link $q$ for link removal scenario; and $S_{B q}=$ speed on link $q$ for base scenario. 


\section{Measuring Network Functionality}

A unified network performance measure for a specified network topology was given by Nagurney and Qiang (2007), the N-Q network efficiency and performance measure as follows:

$$
\varphi=\varphi(\boldsymbol{\aleph}, \mathbf{d})=\frac{\sum_{q \in Q} \frac{d_{q}}{\theta_{q}}}{n_{Q}}
$$

where $\varphi=$ network performance measure; $\boldsymbol{\aleph}=$ network topology; $\mathbf{d}=$ equilibrium volume vector; $d_{q}=$ equilibrium volume for link $q$; $\theta_{q}=$ equilibrium disutility for link $q$ (minimum equilibrium travel time or cost); and $n_{Q}=$ number of O-D pairs in the network.

In this paper, the N-Q measure and a performance index computational approach used by Zhang et al. (2009) were modified and adopted in determining network performance during bridge closures. In this approach, the ratio of congested speeds to free flow speeds for O-D pairs were weighted by VDT and VHT to provide two performance indexes (indicators). The performance metrics formulated in the following are mobility performance metrics for the regional transportation networks:

$$
\begin{aligned}
\mathrm{PI}_{\mathrm{VDT}}=\frac{\sum_{i \in O, j \in D} \frac{\mathrm{CSPD}_{i, j} \mathrm{VDT}_{i, j}}{\mathrm{FFS}_{i, j}}}{\sum_{i \in O, j \in D} \mathrm{VDT}_{i, j}} \\
\mathrm{PI}_{\mathrm{VHT}}=\frac{\sum_{i \in O, j \in D} \frac{\mathrm{CSPD}_{i, j} \mathrm{VHT}_{i, j}}{\mathrm{FFS}_{i, j}}}{\sum_{i \in O, j \in D} \mathrm{VHT}_{i, j}}
\end{aligned}
$$

where $\mathrm{PI}_{\mathrm{VDT}}=\mathrm{VDT}$ weighted performance indicator; $\mathrm{PI}_{\mathrm{VHT}}=\mathrm{VHT}$ weighted performance indicator; $\mathrm{CSPD}_{i, j}=$ congested speed for nodes $i-j$; and $\mathrm{FFS}_{i, j}=$ free flow speed for nodes $i-j$.

Performance measure $\varphi$ is

$$
\varphi_{k}=\frac{\mathrm{PI}_{\text {after_shock }}}{\mathrm{PI}_{\text {before_shock }}}
$$

where $\varphi_{k}=$ performance measure for indicator $k$ (VDT or VHT); $\mathrm{PI}_{\text {after_shock }}=$ VDT or VHT weighted performance indicator after hazard event; and $\mathrm{PI}_{\text {before_shock }}=\mathrm{VDT}$ or VHT weighted performance indicator prior to hazard event.

\section{Computing Single Resilience Index}

The concept of resilience triangle proposed by Bruneau et al. (2003) has been broadly applied in the evaluation of infrastructure resilience over the last decade (Ta et al. 2009; Zobel 2010; Adams et al. 2012). In this concept, the area within the resilience triangle reflects the loss in performance over time, meaning larger areas outside the triangle indicate greater resilience. The community earthquake loss of resilience, $R_{L}$, was mathematically expressed in Eq. (16) as the functional performance of the infrastructure integrated over the recovery period (Bruneau et al. 2003)

$$
R_{L}=\int_{t_{0}}^{t_{1}}[100-Q(t)] d t
$$

where $Q(t)=$ quality of infrastructure $(\%) ; t_{0}=$ time of disruption event; and $t_{1}=$ time of system recovery.

Transportation network resilience depends on vulnerability and adaptive capacity (Gunderson et al. 2002). While vulnerability represents the system's sensitivity to disruption, adaptive capacity evaluates the system's ability to contain shocks. Heaslip et al. (2009) in a proposed resilience cycle identified self-annealing as a stage following network breakdown (network reaching lowest performance level after disruption) where transportation networks accommodate present demand. Self-annealing essentially accounts for gradual increase in network performance levels by road users adapting to new travel paths through alternative route choices until the system reaches a new equilibrium, resulting in possible improvement in network performance (Heaslip et al. 2009). This is typically prior to complete physical system recovery or functionality restoration.

In this paper, the discussed concepts were applied; however, the sensitivity of resilience to recovery time was factored by accounting for expected recovery times based on multilevel hazard-induced bridge damages (Fig. 1). This is important since by definition resilience does not only explain the ability of infrastructure to absorb effects of a hazard but the ability of the system to recover quickly. The original resilience triangle proposed by Bruneau et al. (2003) depicts this clearly. In the context of transportation networks, high performance loss coupled with long recovery times does not only lead to increased transportation user costs, but also accessibility related to societal impacts, especially among aging or frail groups (Twumasi-Boakye et al. 2018). This approach ensures that resilience is not solely defined by functionality losses (a measure of importance), but weighted by the best- and worst-case representations of time to recovery. The ratio of the mean area to mean

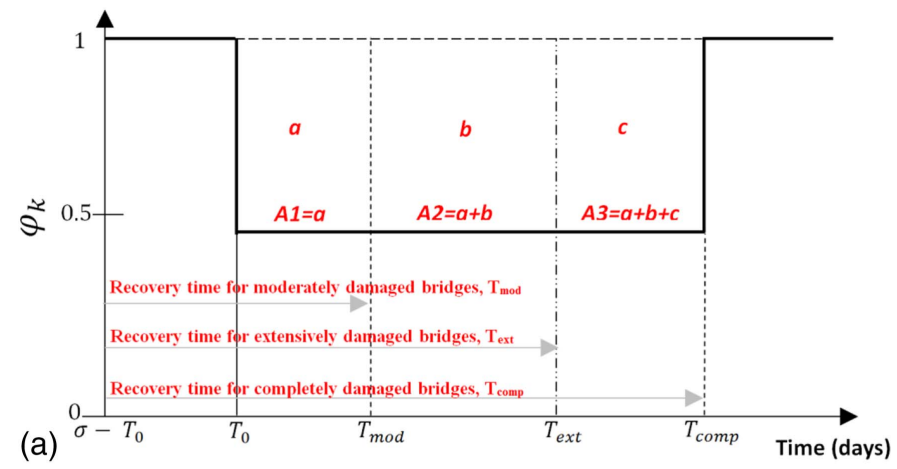

(b)

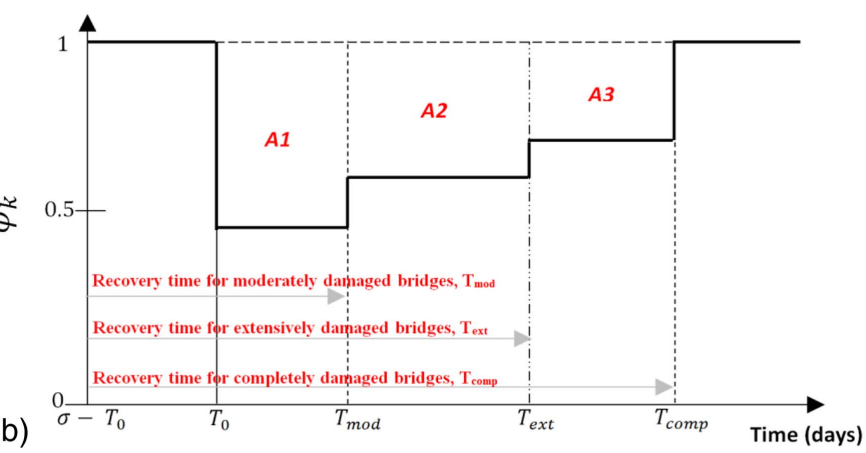

(c)

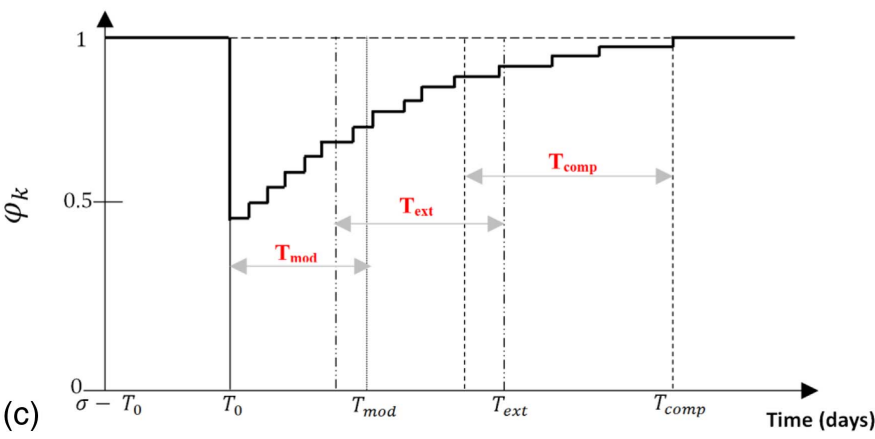

Fig. 1. Transportation network resilience diagrams based on bridge damage. 
recovery time results in an indexed measure. The compliment of the indexed measure yields a resilience index scaled from 0 to 1 , with higher values reflecting more resilient networks.

In Fig. 1(a), $A 1, A 2$, and $A 3$ represent a transportation network's resilience based on hurricane-induced bridge damage states. Detailed descriptions for four identified bridge damage states (slight, moderate, extensive, and complete) were reported by Sobanjo and Thompson (2013). Bridge closures are, however, expected when bridges are moderately, extensively, and completely damaged, hence these damage states were considered in the resilience analysis, similar to Karamlou et al. (2016). Any single bridge can be moderately, extensively, or completely damaged after a hazard event. For pre-event evaluation of resilience, the authors accounted for the three possible damage state outcomes in the resilience computation. Recovery times were expected to vary per damage state. This instance was based on the assumption that the damaged bridge(s) will be opened at the same time. As a result, the transportation network performance measure remained unchanged until recovery. Though this is possible in all cases for single-bridge damage scenarios, damage to multiple bridges will require different recovery schema.

Fig. 1(b) suffices when considering three damaged bridges, each with unique damage states (moderate, extensive, and complete). In the event of three damaged bridges, the moderately, extensively, and completely damaged bridges were modeled to recover in the listed order, leading to total transportation network recovery. Although unlikely, this simplified approach follows in the rare case where multiple bridges with the same damage state happen to recover at the same time. A new transportation network performance was reached when bridges at a specific damage state were restored.
The resilience loss was computed by summing $A 1, A 2$, and $A 3$, since unlike the first case [Fig. 1(a)], performance varies.

Fig. 1(c) depicts the more complex situation of multiple bridge damages. This case reflects the practical case in which bridges of the same damage state may recover at different times. Recovery times in this case may largely depend on the more uncertain agency response practices. The duration of closurewais also influenced by the size of the damaged bridge or the quantity of damaged elements at the same damage level. As a result, Fig. 1(c) includes recovery options where some extensively damaged bridges may recover before moderately damaged bridges, and completely damaged bridges before extensively damaged bridges. The stepwise recovery approximates to the original resilience triangle proposed by Bruneau et al. (2003); however, in this diagram the authors hypothesize that most moderately damaged bridges will be restored rapidly. Again, it is important to state that Fig. 1 describes performance loss and recovery times at various bridge damage states. This performance refers to the transportation network's performance and not bridge structural integrity. Therefore, there is a general assumption that all the mentioned bridge damage states will result in bridge closures, hence the same loss of transportation network functionality when considering individual bridges as in the case of Fig. 1(a) (irrespective of damage state). However, the times to recovery were expected to vary for different bridge damage states, and this influenced network resilience significantly.

The recovery sequence adopted in this study included the assumptions that resources are readily available for bridge repair and rehabilitation activities, and for the application examples, bridges of lower damage states were assumed to recover first as identified in previous literature (Dong et al. 2013).

The resilience formulation applied in this study was as follows:

$$
\begin{aligned}
R_{k}= & 1-\frac{1}{\bar{T}}\left[\int_{0}^{T_{\bmod (h)}}\left[1-\varphi_{k}^{\bmod (h)}(t)\right] d t+\int_{T_{\bmod (h)}}^{T_{\bmod (h+1)}}\left[1-\varphi_{k}^{\bmod (h+1)}(t)\right] d t+\cdots+\int_{T_{\bmod (n-h)}}^{T_{\bmod (n)}}\left[1-\varphi_{k}^{\bmod (n)}(t)\right] d t\right. \\
& +\int_{0}^{T_{\operatorname{ext}(h)}}\left[1-\varphi_{k}^{\operatorname{ext}(h)}(t)\right] d t+\int_{T_{\operatorname{ext}(h)}}^{T_{\operatorname{ext}(h+1)}}\left[1-\varphi_{k}^{\operatorname{ext}(h+1)}(t)\right] d t+\cdots+\int_{T_{\operatorname{ext}(n-h)}}^{T_{\operatorname{ext}(n)}}\left[1-\varphi_{k}^{\operatorname{ext}(n)}(t)\right] d t+\int_{0}^{T_{\operatorname{comp}(h)}}\left[1-\varphi_{k}^{\operatorname{comp}(h)}(t)\right] d t \\
& \left.+\int_{T_{\text {comp }(h)}}^{T_{\operatorname{comp}(h+1)}}\left[1-\varphi_{k}^{\operatorname{comp}(h+1)}(t)\right] d t+\cdots+\int_{T_{\operatorname{comp}(n-h)}}^{T_{\text {comp }(n)}}\left[1-\varphi_{k}^{\operatorname{comp}(n)}(t)\right] d t\right]
\end{aligned}
$$

where $T_{\text {mod }}=$ time for restoring moderately damaged infrastructure in days; $T_{\text {ext }}=$ time for restoring extensively damaged infrastructure in days; $T_{\text {comp }}=$ time for restoring completely damaged infrastructure in days; $\bar{T}=$ mean time for network recovery in days; $\varphi_{k}^{p(h)}(t)=$ performance measure for indicator $k$ for each damage state $h$ [where $p=$ moderate (mod), extensive (ext), and complete (comp) damage states and $h=$ specific bridge(s) under recovery from $p$ damage state]; and $n=$ total number of damaged bridges for each damage state.

For the formulation for single-bridge closure scenarios, performance measures, $\varphi_{k}(t)$, were constant, therefore

$$
R_{k}=1-\frac{1}{\bar{T}}\left[\int_{0}^{T T}\left[1-\varphi_{k}(t)\right] d t\right]
$$

where

$$
T T=\frac{1}{3}\left(T_{\text {mod }}+T_{\text {ext }}+T_{\text {comp }}\right)
$$

The formulation for three bridges (or group of bridges) with unique damage states [Fig. 1(b)] was

$$
\begin{aligned}
R_{k}= & 1-\frac{1}{\bar{T}}\left[\int_{0}^{T_{\text {mod }}}\left[1-\varphi_{k}^{p(h)}(t)\right] d t+\int_{T_{\text {mod }}}^{T_{\text {ext }}}\left[1-\varphi_{k}^{p(h)}(t)\right] d t\right. \\
& \left.+\int_{T_{\mathrm{ext}}}^{T_{\text {comp }}}\left[1-\varphi_{k}^{p(h)}(t)\right] d t\right]
\end{aligned}
$$

The formulation for single bridge closure events with partial recovery prior to full recovery was 


$$
\begin{aligned}
R_{k}= & 1-\frac{1}{3 \bar{T}}\left[\int_{0}^{T_{\bmod (\eta)}}\left[1-\varphi_{k}^{\bmod (\eta)}(t)\right] d t+\int_{T_{\bmod (\eta)}}^{T_{\bmod (\theta)}}\left[1-\varphi_{k}^{\bmod (\theta)}(t)\right] d t\right. \\
& +\int_{0}^{T_{\operatorname{ext}(\eta)}}\left[1-\varphi_{k}^{\operatorname{ext}(\eta)}(t)\right] d t+\int_{T_{\operatorname{ext}(\eta)}}^{T_{\operatorname{ext}(\theta)}}\left[1-\varphi_{k}^{\operatorname{ext}(\theta)}(t)\right] d t \\
& \left.+\int_{0}^{T_{\operatorname{comp}(\eta)}}\left[1-\varphi_{k}^{\operatorname{comp}(\eta)}(t)\right] d t+\int_{T_{\operatorname{comp}(\eta)}}^{T_{\operatorname{comp}(\theta)}}\left[1-\varphi_{k}^{\operatorname{comp}(\theta)}(t)\right] d t\right]
\end{aligned}
$$

where $\eta=$ partial recovery; and $\theta=$ complete recovery.

Closure durations for previously recorded bridge closure events were obtained (Table 1) and used to establish the aforementioned recovery times. The recovery times reported are samples from internet queries and a limitation in this study because agencies presently do not have databases for hazard-induced bridge closure durations. These values were used in assigning mean closure times (time to recovery) to the specified bridges in this study. The estimated mean recovery times for interstate and non-interstate bridges were estimated as 61.7 and 59.7 days, respectively. In the case of moderate, extensive, and complete damages, the recovery times were $3,48.5$, and 133 days, respectively, for interstate bridges, and 1, 30, and 173 days for noninterstate bridges.

With the aim of developing a single indicator value for resilience, the equal weighting approach was used. This method has been used for computing composite indexes (Estoque and Murayama 2014) and organizational resilience (Briguglio et al. 2009). Ip and Wang (2009) represented nodes and links in a transportation network as towns and roadways, respectively, by representing the network as an undirected graph. In this research, the weighted average and weighted sum approaches for estimating city node resilience and network resilience were used. The choice of an undirected graph suffices for road transportation networks where bidirectional flows are typical. Furthermore, the links in the undirected network have different lengths and capacities hence were weighted. Directed networks only allow flows in one direction, and hence are more suited for studies on railway systems. When estimating city node resilience, Ip and Wang (2009) considered the number of reliable independent paths connecting all other town nodes within the network. The network resilience was then determined by combining all nodes. The equal weighting method was used in this study since it is straightforward and succinct. The formulation is as follows:

$$
W=\frac{\sum_{k=1}^{n} R_{k}}{n}
$$

where $R_{k}=$ resilience index measure for each computed indicator, $k$; and $n=$ total number of index indicators.

\section{Application Example}

The area for this study is known as the Tampa Bay Region in Florida; an area prone to hurricane strikes and storm surges as seen in Fig. 2. Tampa Bay is a vast natural harbor and estuary that is linked to the Gulf of Mexico on the west central coast of Florida. Being home to approximately 4 million residents, Tampa Bay is a heavily utilized commercial and recreational waterway. Having four ports, Tampa Bay is regarded as a very important shipping

\begin{tabular}{|c|c|c|c|c|c|c|}
\hline Hazard event & Closed bridge & Date closed & Date opened & Location & $\begin{array}{l}\text { Partial } \\
\text { restoration } \\
(\text { days })\end{array}$ & $\begin{array}{c}\text { Total closure } \\
\text { duration } \\
\text { (days) }\end{array}$ \\
\hline Hurricane Katrina & I-10 twin spans over Lake Pontchartrain & August 29, 2005 & January 5, 2006 & Louisiana & 46 & 83 \\
\hline Hurricane Katrina & I-10 West Pascagoula bridges & August 29, 2005 & October 2, 2005 & Mississippi & 20 & 31 \\
\hline Hurricane Katrina & $\begin{array}{l}\text { I-10 (Mobile Bayway) and US-90 and } \\
\text { US-98 (Battleship Causeway) }\end{array}$ & August 29, 2005 & September 2, 2005 & Alabama & - & 3 \\
\hline Hurricane Katrina & $\begin{array}{l}\text { I-10 (Mobile Bayway) and US-90 and } \\
\text { US-98 (Battleship Causeway) }\end{array}$ & August 30, 2005 & February 26, 2006 & Alabama & - & 180 \\
\hline Hurricane Ivan & I-10 bridge over Escambia Bay & September 16, 2004 & November 20, 2004 & Florida & 17 & 66 \\
\hline Hurricane Matthew & US-74 interstate 95 & October 10, 2016 & October 17, 2016 & North Carolina & - & 7 \\
\hline Hurricane Ivan & Bob Sikes Bridge & September 16, 2004 & September 22, 2004 & Florida & - & 6 \\
\hline Hurricane Ivan & Navarre Beach Causeway & September 16, 2004 & November 3, 2004 & Florida & - & 48 \\
\hline Hurricane Ivan & US-98 Pensacola Bay Bridge & September 16, 2004 & September 21, 2004 & Florida & - & 5 \\
\hline Hurricane Ivan & Garcon Point Bridge & September 16, 2004 & September 22, 2004 & Florida & - & 6 \\
\hline Hurricane Ivan & US-98 Lillian Highway Bridge & September 16, 2004 & February 19, 2005 & Florida & 17 & 137 \\
\hline Hurricane Ivan & US-90 Escambia river causeway & September 16, 2004 & September 22, 2004 & Florida & 1 & 6 \\
\hline Hurricane Ivan & Florida State Road 292 Perdido Key Bridge & September 16, 2004 & January 2005 & Florida & - & 120 \\
\hline Hurricane Ivan & Florida State Road 196 (Bayfront Parkway) & September 16, 2004 & December 2004 & Florida & - & 100 \\
\hline Hurricane Ivan & Florida State Road 291 (Davis Highway) & September 16, 2004 & September 17, 2004 & Florida & - & 1 \\
\hline Hurricane Ivan & US-98 in Santa Rosa County & September 16, 2004 & September 17, 2004 & Florida & - & 1 \\
\hline Hurricane Ivan & Florida State Road 87 & September 16, 2004 & September 17, 2004 & Florida & - & 1 \\
\hline Hurricane Katrina & Chef Menteur Pass Bridge & August 29, 2005 & November 30, 2005 & Louisiana & - & 100 \\
\hline Hurricane Katrina & $\begin{array}{l}\text { US-90 and US-98 Truck } \\
\text { Cochrane-Africatown Bridge }\end{array}$ & August 29, 2005 & August 31, 2005 & Alabama & - & 2 \\
\hline Hurricane Katrina & Bayou Liberty Bridge, LA-433 & August 29, 2005 & February 2006 & Louisiana & - & 180 \\
\hline Hurricane Katrina & Bayou Barataria, LA-302 & August 29, 2005 & September 5, 2005 & Louisiana & - & 7 \\
\hline Hurricane Katrina & Rigolets, US-90 & August 29, 2005 & September 28, 2005 & Louisiana & - & 30 \\
\hline Hurricane Katrina & East Pearl River, US-90 & August 29, 2005 & September 28, 2005 & Louisiana & - & 30 \\
\hline Hurricane Katrina & Henderson Point, US-90 & August 29, 2005 & January 24, 2007 & Mississippi & - & 172 \\
\hline Hurricane Katrina & Popps Ferry & August 29, 2005 & December 23, 2005 & Mississippi & - & 176 \\
\hline
\end{tabular}
center. Bridges moving across this bay are of high importance for mobility, and bridge damages are projected to have a

Table 1. Bridge closure durations after hurricane events (sample data) 


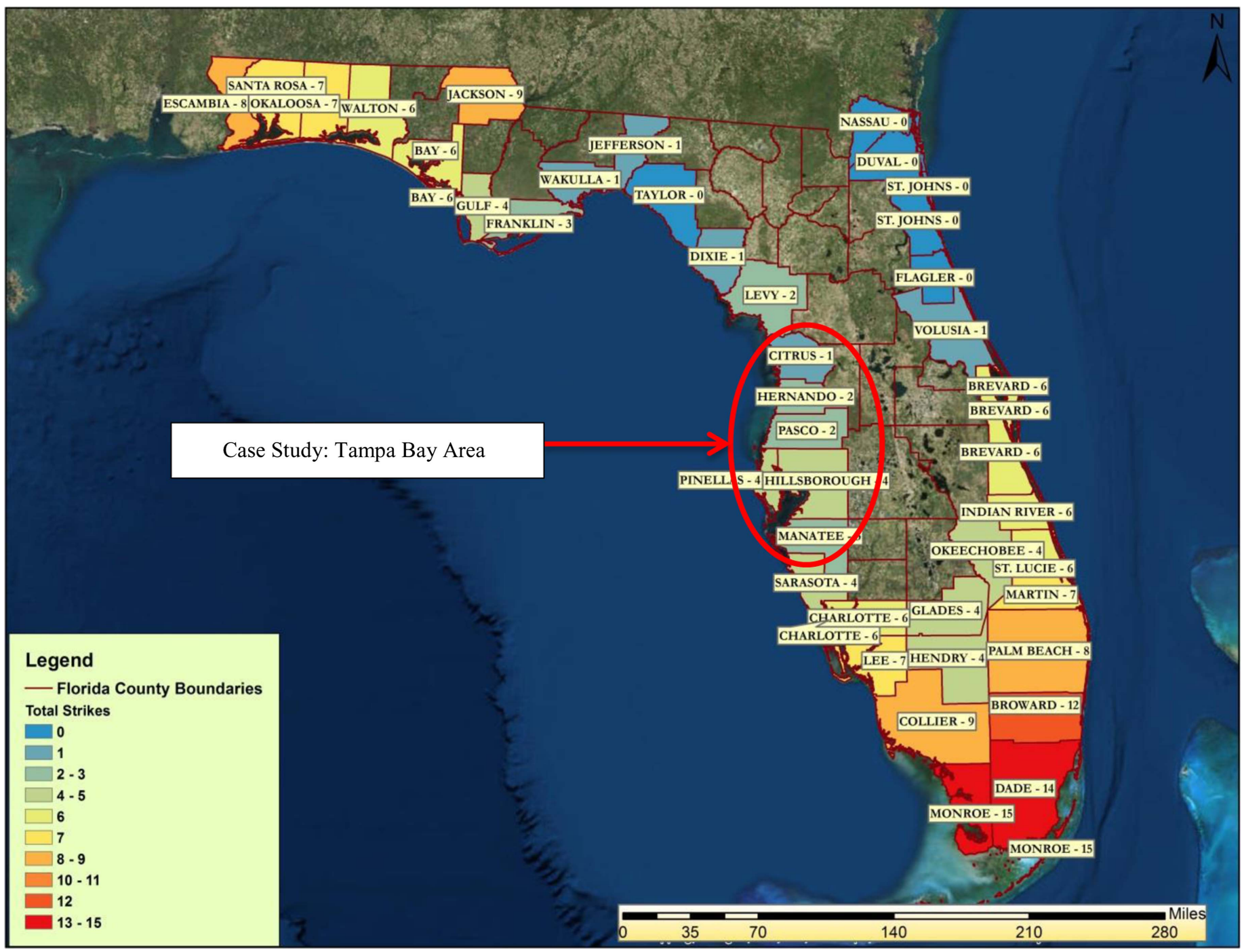

Fig. 2. Total number of major hurricane strikes (1900-2010) by Florida county developed using ArcGIS software. (Data from National Hurricane Center 2016.)

debilitating impact on the transportation network, leading to potential accessibility issues (Twumasi-Boakye et al. 2018). Details of the transportation network configuration and regional model are subsequently discussed in this paper.

\section{Network Configuration}

The network model adopted for this study was the Tampa Bay Regional Planning Model (TBRPM) version 7.2, a regional model developed under the Regional Transportation Analysis (RTA) for planning activities (Gannett Fleming 2010). The study area corresponds to the jurisdiction of the Florida Department of Transportation (FDOT), District 7, and includes Hillsborough, Pinellas, Pasco, Hernando, Citrus, and Manatee counties of Florida. There exists heavy trip interchange between southern Hillsborough and Pinellas counties, making the bridges connecting these areas of high importance. Fig. 3 shows the network configuration. This network is composed of 31,797 links and 3,029 zones, with 29 of these zones representing external stations. Traffic assignment was executed using Cube Voyager 6.1.1 simulation software by Citilabs. The population of the RTA study area was more than 2.8 million in 2006 , reflecting an annual growth rate of approximately $2 \%$ since
2000. The travel forecasting process used in the model was the already mentioned 4-step travel demand forecasting process. The model was obtained from the Florida Standard Urban Transportation Model Structure (FSUTMS). Bridge locations and county jurisdictions were also obtained as shapefiles from the Florida Geographic Data Library (FGDL).

\section{Network Scenario Modeling}

In initial studies, five bridge closure scenarios were considered in order to determine and compare resilience indicators. The five bridges considered are labeled in Fig. 3 and identified as Sunshine Skyway Bridge (SSB), Bayside Bridge (BAY-B), I-275 bridge (I-275B), Gandy Bridge (GB), and West Courtney Campbell Causeway (WCB). Selection of these bridges was based on their critical location to mobility and commercial activity within the Tampa Bay area. Furthermore, these bridges are cross-waterbody structures hence are at higher risk to hazard-induced (hurricane) damages. Fig. 4 indicates the high traffic volumes at these bridge locations. This implies that closure to any of them will have an observable effect on the transportation network. This is true because they serve as links between Pinellas and Hillsborough counties 


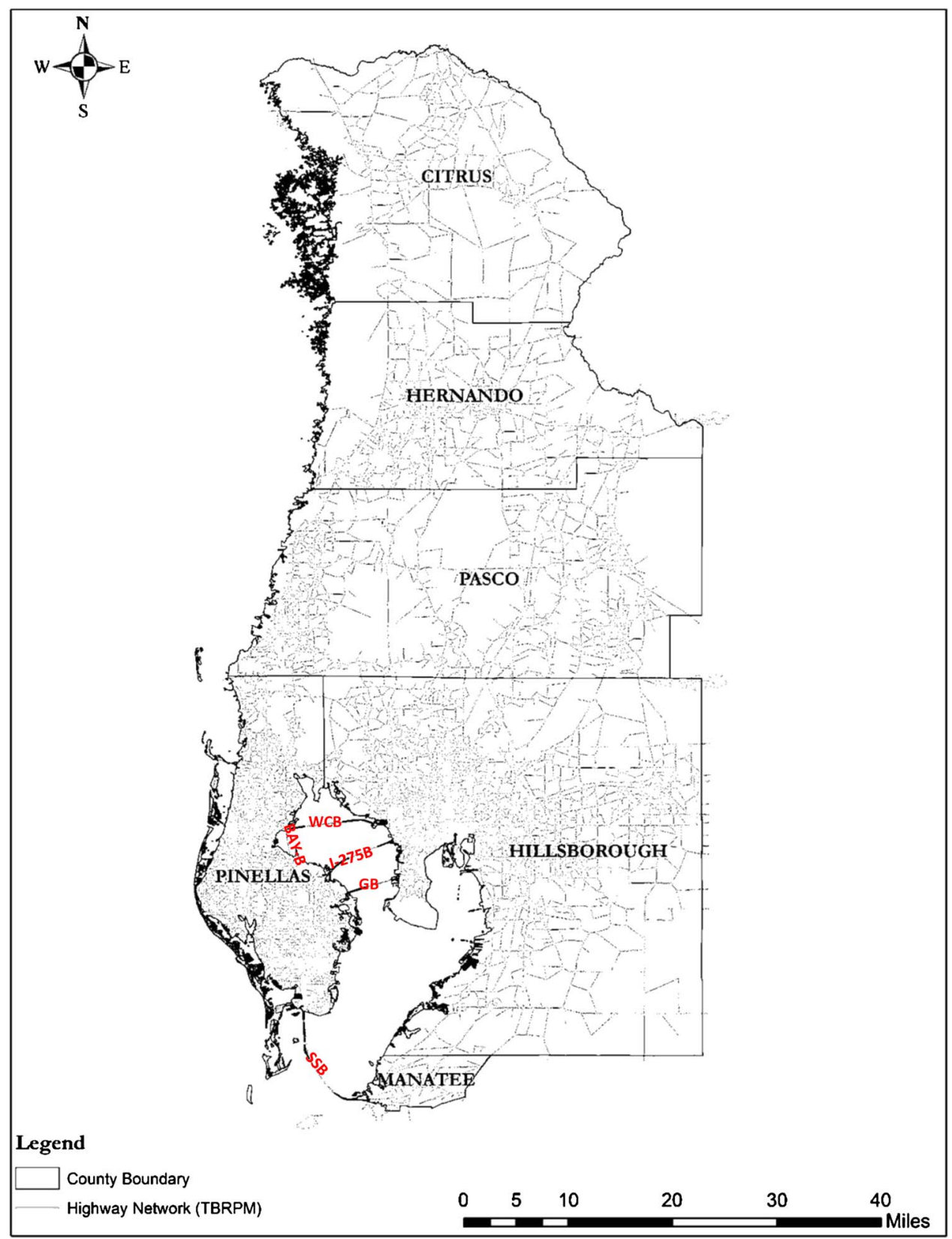

Fig. 3. Map showing the regional transportation network for the case study area.

as well as Pinellas and Manatee counties. Initial analysis served as the basis for further studies involving Pinellas, Hillsborough, and Manatee counties, which included the closure to the I-275 westbound (WB) bridge and closure to both I-275 and Gandy bridges.

Ten scenarios and recovery sequences were considered in the final analysis, and results are summarized in Table 4. For each damage scenario, the damaged bridge was closed in the network models in Cube Voyager and the regional model was rerun until a new equilibrium was reached. This process was repeated for all closure scenarios to obtain new link travel times, VHT and VDT. Unlike small networks, computational costs involved in modeling regional networks are high and data postprocessing is involved. For high-impact-zone analysis, model outputs for damage scenarios were matched with uninterrupted network data prior to computing speed reduction for each link. This data were then imported into ArcMap version 10.2, a GIS-based application for visualization.

\section{Results and Discussion}

As part of preliminary analyses, traffic volumes at the specified bridge locations were compared with average annual daily traffic (AADT) and peak season weekday average daily traffic (PSWADT). The AADT data for Florida roadways were obtained from FDOT and PSWADT values were retrieved as model outputs computed for each link in the TBRPM. This was done to validate that the volume outputs from the model were comparable to traffic counts. Results are seen in Fig. 4.

The initial analyses were done primarily to determine practical performance indicators. While travel times were considered an obvious measure of travel, VHT and VDT were determined as 
efficient for the large network since both metrics captured traffic volumes on all links. In addition, the mean link speed reduction metric was applied in this step to help identify the high-impactarea zones where further analysis may be warranted. Enhanced visualization using GIS analysis tools was adopted to determine

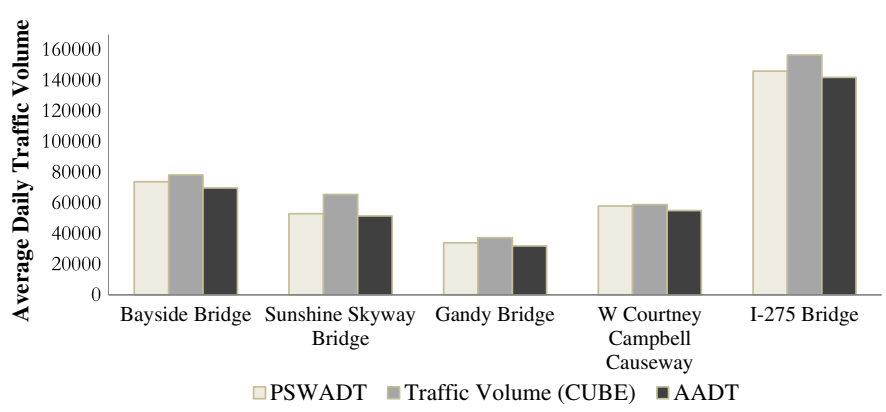

Fig. 4. Cube Voyager traffic volume outputs and traffic counts at bridge locations. model variations from the base (undisrupted) model and identify links of speed reduction. The visualization approach adopted in this research was essential since it served as an efficient way to preliminarily evaluate and communicate the effects of the bridge closures on the regional transportation network prior to other numerical computations.

Figs. 5(a-c) reflect the results of a network analysis involving movement between Pinellas and Hillsborough counties. Results are demonstrated as shortest path routing between an origin and destination zones from Pinellas to Hillsborough counties depicted by 10-min isochrones. The total travel time for the selected route was also determined and compared. Outcomes as seen in Figs. 5( $\mathrm{a}$ and $\mathrm{b}$ ) indicate travel times of 46.1 and $64.6 \mathrm{~min}$ for FFTT and CTT, respectively, for the base scenario. Fig. 5(c) indicates an enormous increase in the shortest alternative path travel time for the I-275 bridge closure scenario, which was estimated as $109.86 \mathrm{~min}$ (approximately an hour more than free flow travel time for the base model and 45 min more than the CTT base scenario). Total regional travel time increased by approximately $440 \mathrm{~min}$ and VDT increased from $121.34 \times 10^{6}$ to $122.51 \times 10^{6}$ vehicle-kilometers (veh-km),

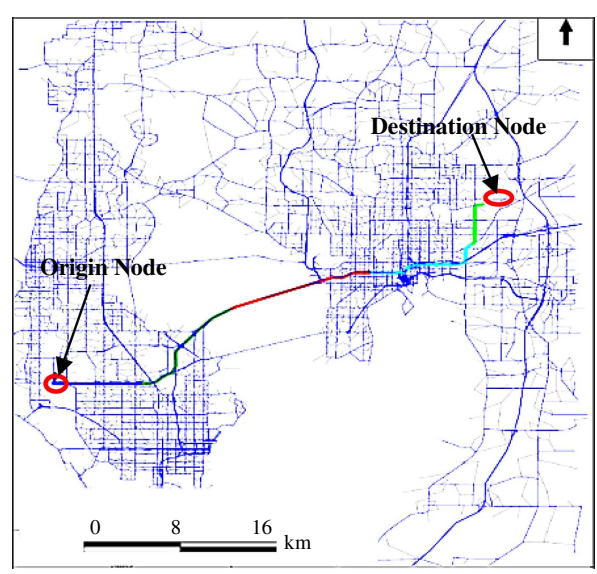

(a)

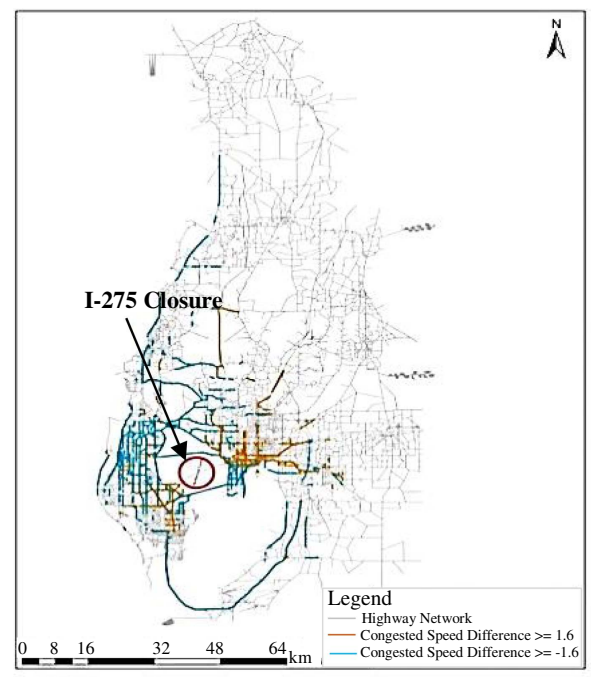

(d)

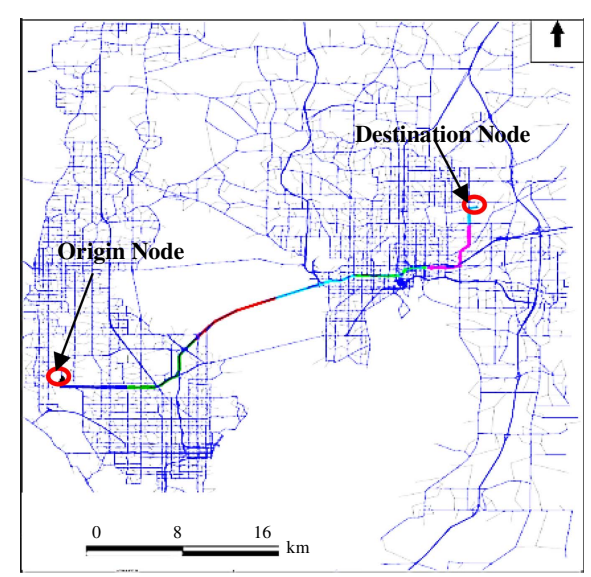

(b)

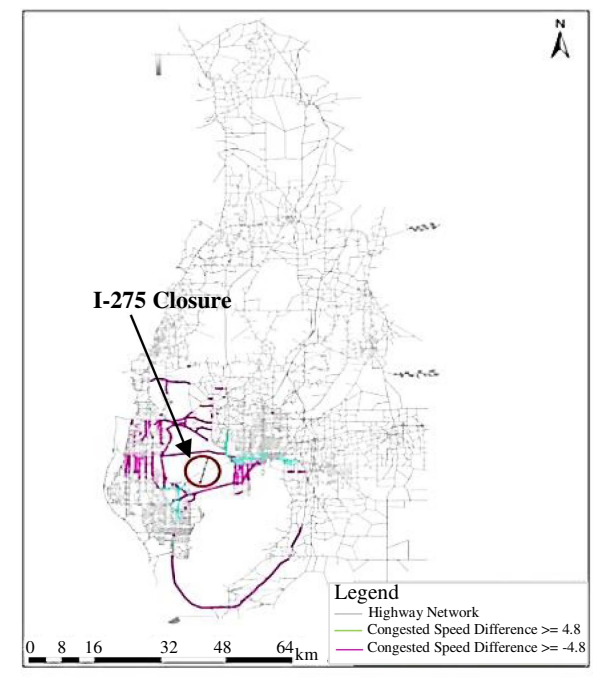

(e)

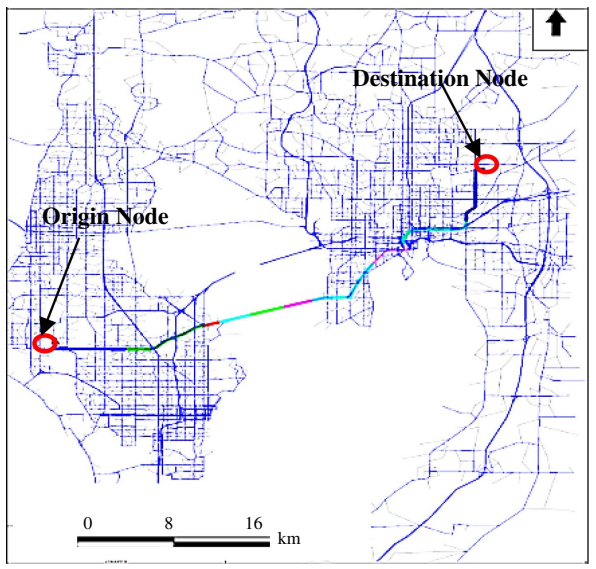

(c)

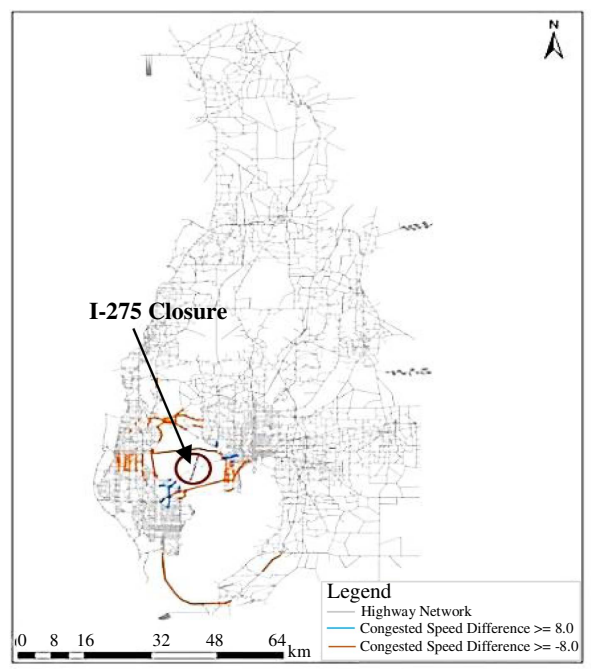

(f)

Fig. 5. Maps showing the shortest path for TBRPM scenarios after I-275 closure and high-impact areas: (a) shortest path for unloaded network for O-D pair at 10-min isochrone increments (46.11 min); (b) shortest path (CTT) for loaded network for O-D pair at 10-min isochrone increments (64.6 min); (c) shortest path (CTT) (I-275 bridge closure) for O-D pair at 10-min isochrone increments (109.86 min); (d) speed difference [1.61 km/h $(1 \mathrm{mi} / \mathrm{h})$ cutoff]; (e) speed difference $[4.83 \mathrm{~km} / \mathrm{h}(3 \mathrm{mi} / \mathrm{h})$ cutoff]; and (f) speed difference $[8.05 \mathrm{~km} / \mathrm{h}(5 \mathrm{mi} / \mathrm{h}) \mathrm{cutoff}]$. 
Table 2. Illustrative results for I- 275 bridge closure

\begin{tabular}{|c|c|c|c|c|c|c|}
\hline Bridge & $\begin{array}{l}\text { Length } \\
(\mathrm{km})\end{array}$ & $\begin{array}{c}\text { Free flow } \\
\text { speed }(\mathrm{km} / \mathrm{h})\end{array}$ & $\begin{array}{c}\text { Congested } \\
\text { speed }(\mathrm{km} / \mathrm{h})\end{array}$ & $\begin{array}{c}\text { Travel } \\
\text { time (min) }\end{array}$ & $\begin{array}{c}\text { Total } \\
\text { VHT (veh-h) }\end{array}$ & $\begin{array}{c}\text { Total } \\
\text { VDT (veh-km) }\end{array}$ \\
\hline \multicolumn{7}{|l|}{ Uninterrupted network } \\
\hline West Courtney Campbell Causeway & 13.71 & 88.51 & 48.06 & 15.48 & $15,196.05$ & $808,274.82$ \\
\hline Bayside & 4.99 & 75.63 & 52.32 & 5.72 & $7,472.69$ & $391,002.05$ \\
\hline Gandy & 8.93 & 72.42 & 65.16 & 8.23 & $5,137.87$ & $334,757.48$ \\
\hline Highway 580 & 1.96 & 53.11 & 18.93 & 6.18 & $3,873.93$ & $73,685.02$ \\
\hline Sunshine Skyway eastbound & 15.16 & 88.51 & 48.22 & 17.63 & $9,575.85$ & $494,209.73$ \\
\hline Sunshine Skyway westbound & 15.29 & 88.51 & 50.89 & 17.99 & $9,892.45$ & $504,239.58$ \\
\hline I-275 eastbound & 9.37 & 80.47 & 51.40 & 10.94 & $14,254.78$ & $732,753.64$ \\
\hline I-275 westbound & 9.25 & 80.47 & 51.66 & 10.74 & $14,040.60$ & $725,315.09$ \\
\hline \multicolumn{7}{|l|}{ Complete closure to I-275 bridge } \\
\hline West Courtney Campbell Causeway & 13.71 & 88.51 & 19.46 & 40.71 & $61,117.15$ & $1,235,913.07$ \\
\hline Bayside & 4.99 & 75.63 & 30.03 & 9.97 & $17,808.58$ & $534,830.70$ \\
\hline Gandy & 8.93 & 72.42 & 17.82 & 30.04 & $42,856.57$ & $765,209.77$ \\
\hline Highway 580 & 1.96 & 53.11 & 8.34 & 14.07 & $11,480.72$ & $95,934.49$ \\
\hline Sunshine Skyway eastbound & 15.16 & 88.51 & 39.25 & 22.37 & $15,677.87$ & $15,4391.60$ \\
\hline Sunshine Skyway westbound & 15.29 & 88.51 & 40.76 & 22.46 & $15,656.51$ & $639,325.97$ \\
\hline \multicolumn{7}{|l|}{ Partial closure to I-275 bridge (WB) } \\
\hline West Courtney Campbell Causeway & 13.71 & 88.51 & 44.50 & 16.82 & $17,507.60$ & $857,029.06$ \\
\hline Bayside & 4.99 & 75.63 & 48.41 & 6.18 & $8,654.16$ & $418,870.90$ \\
\hline Gandy & 8.93 & 72.42 & 54.77 & 9.78 & $7,947.57$ & $435,976.76$ \\
\hline Highway 580 & 1.96 & 53.11 & 19.55 & 5.98 & $3,733.23$ & $73,417.47$ \\
\hline Sunshine Skyway eastbound & 15.16 & 88.51 & 48.47 & 17.53 & $9,549.24$ & $495,642.31$ \\
\hline Sunshine Skyway westbound & 15.29 & 88.51 & 51.05 & 17.94 & $9,839.49$ & $503,056.52$ \\
\hline I-275 eastbound & 9.37 & 80.47 & 29.27 & 19.19 & $22,984.76$ & $673,535.54$ \\
\hline
\end{tabular}

Table 3. Aggregated resilience index

\begin{tabular}{|c|c|c|c|c|c|c|c|c|c|}
\hline Network & Total VHT (veh-h) & Total VDT (veh-km) & $\mathrm{PI}_{\mathrm{VHT}}$ & $\mathrm{PI}_{\mathrm{VDT}}$ & $\phi_{\text {PIVHT }}$ & $\phi_{\text {PIVDT }}$ & $T_{\text {mod }}$ (days) & $T_{\text {ext }}$ (days) & $T_{\text {comp }}$ (days) \\
\hline Uninterrupted & $79,444.22$ & $4,064,237.40$ & 0.61 & 0.62 & 1 & 1 & - & - & - \\
\hline Complete I-275 closure & $164,597.4$ & $3,909,284.10$ & 0.29 & 0.32 & 0.47 & 0.53 & 3 & 48.5 & 133 \\
\hline Partial I-275 closure & $80,216.06$ & $3,457,528.55$ & 0.51 & 0.54 & 0.84 & 0.88 & 1 & 18.5 & 33 \\
\hline
\end{tabular}

Note: $R_{\mathrm{VHT}}=0.468 ; R_{\mathrm{VDT}}=0.527 ;$ and $\mathrm{ARI}=0.498$.

while VHT increased from $289 \times 10^{4}$ to $312 \times 10^{4}$ vehicle-hours (veh-h).

Percentage reduction (or increase) in speeds for the selected links based on the speed differences were computed and weighted to determine the average percentage link speed reduction for the bridge closure scenarios [Eq. (11)]. Figs. 5(d-f) provide visualizations for average percentage link speed reductions for the I-275 bridge closure scenario. Results depict highway links with increase (or decrease) in speed differences equal to or greater than $1.61 \mathrm{~km} / \mathrm{h} \quad(1 \mathrm{mi} / \mathrm{h}), \quad 4.83 \mathrm{~km} / \mathrm{h} \quad(3 \mathrm{mi} / \mathrm{h})$, and $8.05 \mathrm{~km} / \mathrm{h}$ $(5 \mathrm{mi} / \mathrm{h})$, respectively. It was observed that a closure to the I-275 bridge leads to considerable reduction in congested speeds on the other four bridge locations. Pinellas County and neighboring locations close to the bridges also reflect reduction in congested speed.

Further analyses were performed to compute the aggregated resilience index. The subsequent steps specifically focused on the identified high-impact regions, that is, Pinellas, Hillsborough, and Manatee counties. Index values were then estimated using Eqs. (13)-(21). A numerical illustration of this approach is seen in Tables 2 and 3. In this illustration, the uninterrupted network was initially disrupted by complete closure to the I-275 bridge, resulting in reduced functionality. Second, the eastbound direction of the I-275 bridge was reopened, and this represents the case of partial closure (only the I-275 WB remained closed). Finally, the entire bridge was reopened as the transportation system returned to pre-event functionality. The computed resilience index was based on pertinent bridges connecting Pinellas and Hillsborough counties.

Fig. 6 diagrammatically explains the computation of resilience indexes for the three scenarios described in this paper. Fig. 6(a), which depicts partial closure to I-275 for VHTbased performance, is typical for closures to West Courtney Campbell Causeway and the Gandy, Sunshine Skyway, and Bayside bridges, the main difference being recovery times. Fig. 6(c) represents the resilience diagram for I-275 closure with partial restoration (recovery) prior to complete bridge restoration.

Computations for Fig. 6 are as follows:

For Fig. 6(a)

$$
\begin{aligned}
\mathrm{A} 1 & =3 \times(1-0.843)=0.471 ; \\
\mathrm{A} 2 & =48.5 \times(1-0.843)=7.615 ; \\
\mathrm{A} 3 & =133 \times(1-0.843)=20.881 \\
R_{\mathrm{VHT}} & =(1-1 / 3 \times(0.471+7.615+20.881) / 61.7)=0.8435 \\
\mathrm{~A} 1 & =3 \times(1-0.878)=0.366 ; \\
\mathrm{A} 2 & =48.5 \times(1-0.878)=5.917 ; \\
\mathrm{A} 3 & =133 \times(1-0.878)=16.226 \\
R_{\mathrm{VDT}} & =(1-1 / 3 \times(0.366+5.917+16.226) / 61.7)=0.8784
\end{aligned}
$$

Aggregate Resilience Index $=\operatorname{average}\left(R_{\mathrm{VHT}}, R_{\mathrm{VDT}}\right)=0.861$ 
For Fig. 6(b)

$$
\begin{aligned}
& \mathrm{A} 1=3 \times(1-0.466)=1.602 ; \\
& \mathrm{A} 2=48.5 \times(1-0.466)=25.899 ; \\
& \mathrm{A} 3=133 \times(1-0.466)=71.022 \\
& R_{\mathrm{VHT}}=(1-1 / 3 \times(1.602+25.899+71.022) / 61.7)=0.468 \\
& \mathrm{~A} 1=3 \times(1-0.525)=1.425 ; \\
& \mathrm{A} 2=48.5 \times(1-0.525)=23.038 ; \\
& \mathrm{A} 3=133 \times(1-0.525)=63.175 \\
& R_{\mathrm{VDT}}=(1-1 / 3 \times(1.425+23.038+63.175) / 61.7)=0.527 \\
& \text { Aggregate Resilience Index }=\text { average }\left(R_{\mathrm{VHT}}, R_{\mathrm{VDT}}\right)=0.498
\end{aligned}
$$

For Fig. 6(c)

$$
\begin{aligned}
\mathrm{A} 1 & =(1 \times(1-0.466))+(2 \times(1-0.843))=0.848 ; \\
\mathrm{A} 2 & =(18.5 \times(1-0.466))+(30 \times(1-0.843))=14.589 ; \\
\mathrm{A} 3 & =(33 \times(1-0.466))+(100 \times(1-0.843))=33.322 \\
R_{\mathrm{VHT}} & =(1-(\mathrm{A} 1+\mathrm{A} 2+\mathrm{A} 3) /(3 \times 61.7))=0.737 \\
\mathrm{~A} 1 & =(1 \times(1-0.525))+(2 \times(1-0.878))=0.719 ; \\
\mathrm{A} 2 & =(18.5 \times(1-0.525))+(30 \times(1-0.878))=12.448 ; \\
\mathrm{A} 3 & =(33 \times(1-0.525))+(100 \times(1-0.878))=27.875 \\
R_{\mathrm{VDT}} & =(1-(\mathrm{A} 1+\mathrm{A} 2+\mathrm{A} 3) /(3 \times 61.7))=0.778
\end{aligned}
$$$$
\text { Aggregate Resilience Index }=\operatorname{average}\left(R_{\mathrm{VHT}}, R_{\mathrm{VDT}}\right)=0.758
$$

Table 4 shows results for index computations for each metric. Closure to the I-275 bridge was observed to result in a noticeable increase in travel time as well as VHT. It was, however, detected that in most cases, indicators relating to travel time demonstrated higher index values compared with those involving vehicle distance traveled. This observation is attributed to the fact that increases in travel times are very prominent during congested conditions when traveling a fixed distance, meaning that during bridge closure occurrences, rerouting through an alternative path may only increase travel distance to the point of the physical length of that alternative network route, which does not necessarily change significantly; hence, while travel time could double for a trip, travel distance does not behave in the same fashion. This is clearly observed with the I-275 bridge closure scenario in which VHT-related performance was much lower than VDT-related performance. Both metrics are, however, important since delay and operating costs vary when evaluating user costs.

The aggregated network resilience index seen in Table 4 is scaled from 0 to 1 , with 1 indicative of no change from existing conditions, or an uninterrupted network, and 0 representing a network with severe performance deficits. Results show that complete closure to the I- 275 bridge results in a low resilience index of 0.498 , representing significant reduction in network performance. Closure to the West Courtney Campbell Causeway, however, results in a network-level resilience index value of 0.87 , while the indexes for the other scenarios range between 0.76 and 0.97 . These results reflect the high dependency of the network on the I-275 bridge. Damage to this bridge is envisaged to have a massive impact on the network in terms of travel cost. Lower resilience index values imply increased loss in resilience, which communicates either significant functionality losses or lengthy closure durations or both. Travel costs were therefore observed to increase when resilience
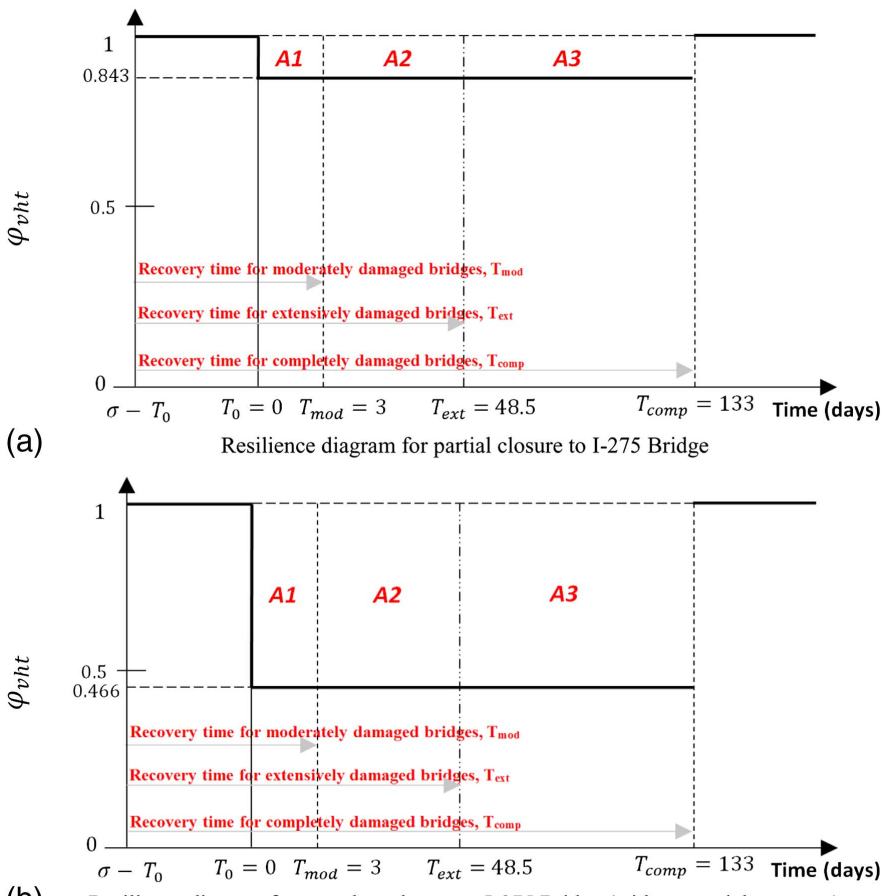

(b) Resilience diagram for complete closure to I-275 Bridge (without partial recovery)

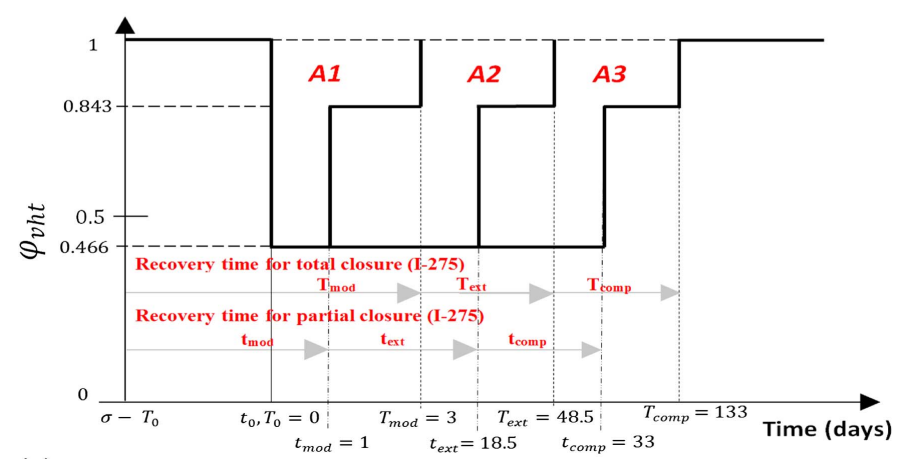

(c) Resilience diagram for complete closure to I-275 Bridge (partial recovery included)

Fig. 6. Resilience diagrams illustrating I-275 bridge closure scenarios (not to scale).

indexes were lower, suggesting an increase in transportation user costs and limitations in mobility.

\section{Conclusions}

In this paper, a framework and computational approach for evaluating the resilience of regional transportation networks has been developed. This method provides a preliminary identification of zones that have been most impacted in the transportation network during bridge closure events. A new metric has been developed that identifies areas for immediate action (high-impact zones) by locating regions with minimal to high mean link speed reductions. The relevance of the proposed metric is stressed for a regional analysis for large networks and serves as pointers to areas that require further resilience evaluation. The use of scenario-based modeling in Cube Voyager and GIS visualization techniques will aid in communicating the specific locations to direct immediate attention after hazard occurrence to responsible agencies.

The aggregated resilience index developed in this study utilized metrics mainly used in transportation user cost computations, i.e., the VDT and VHT. These metrics were combined with 
Table 4. Performance index and resilience index for bridge closure scenarios

\begin{tabular}{|c|c|c|c|c|c|c|c|}
\hline Scenario & Bridge closure & Recovery sequence & $\mathrm{PI}_{\mathrm{VHT}}$ & $\mathrm{PI}_{\mathrm{VDT}}$ & $R_{\mathrm{VHT}}$ & $R_{\mathrm{VDT}}$ & ARI \\
\hline 1 & I-275 bridge complete & Total recovery & 0.466 & 0.525 & 0.468 & 0.527 & 0.498 \\
\hline 2 & I-275 bridge partial & Total recovery & 0.843 & 0.878 & 0.844 & 0.878 & 0.861 \\
\hline 3 & I-275 bridge complete & Partial-total recovery & - & - & 0.737 & 0.778 & 0.758 \\
\hline 4 & Gandy Bridge complete & Total recovery & 0.898 & 0.894 & 0.883 & 0.879 & 0.881 \\
\hline 5 & Sunshine Skyway Bridge complete & Total recovery & 0.983 & 0.989 & 0.981 & 0.987 & 0.984 \\
\hline 6 & West Courtney Campbell Causeway Bridge complete & Total recovery & 0.882 & 0.897 & 0.865 & 0.882 & 0.873 \\
\hline 7 & Bayside Bridge complete & Total recovery & 0.976 & 0.974 & 0.973 & 0.970 & 0.971 \\
\hline 8 & I-275 and Gandy Bridges complete & Total recovery & 0.365 & 0.403 & 0.367 & 0.405 & 0.386 \\
\hline 9 & I-275 and Gandy Bridges complete & Gandy Bridge-total recovery & - & - & 0.370 & 0.431 & 0.401 \\
\hline 10 & I-275 and Gandy Bridges complete & $\begin{array}{l}\text { Gandy Bridge - partial } \\
\text { I-275-total recovery }\end{array}$ & - & - & 0.670 & 0.702 & 0.686 \\
\hline
\end{tabular}

congested speeds and free flow speeds to provide a performance metric used to measure resilience. This is a modification of the mobility performance index based on truck distance traveled developed by Zhang et al. (2009). This modified index explains regional mobility effects or changes based on both distance traveled and time traveled. The development of the index accounted for the use of recovery times based on expected damage states for bridges. The authors believe that the developed aggregated index is effective in capturing resilience based on varying recovery times.

Findings from an application example on the Tampa Bay, Florida, regional network reflected significant regional resilience losses when analyzed for bridge closures. Closure to the I-275 bridge was observed to have the most significant impact on the network because the resilience index was less than 0.5 , signifying severe network functionality losses, increase in delays, and mobility limitations. This substantial loss is, however, minimized when recovery efforts included partial (one direction) restoration of the bridge prior to complete recovery. The resilience index improved to 0.758 .

The importance of the I-275 bridge to the network was further reinforced when even partial (westbound direction) operation of the bridge indicated a resilience index (0.861) comparable to complete closures to Gandy Bridge (0.881) and West Courtney Campbell Causeway (0.873). These findings are relevant in ensuring that measures are put in place to contain the effects of unforeseen closures to such important bridges, whether in the event of hurricanes or other potential hazards. Findings show possibilities of traffic gridlocks on several roadways in the Pinellas and Hillsborough counties in the event of closure to the I-275 bridge.

The authors recommend that future work should focus on investigating the influence of alternative modes of travel as a measure of redundancy in improving network resiliency during bridge and road closures. Regional-level studies are encouraged due to the ripple effects of closures on ignored sections on regional networks. Agencies are also encouraged to keep records of bridge closure durations, especially after hazard events, because this will help in research studies on the recovery phase of resilience and will allow the proper calculations during implementation of the proposed approach.

\section{References}

Adams, T. M., K. R. Bekkem, and E. J. Toledo-Durán. 2012. "Freight resilience measures." J. Transp. Eng. 138 (11): 1403-1409. https://doi.org /10.1061/(ASCE)TE.1943-5436.0000415.

Adjetey-Bahun, K., B. Birregah, E. Châtelet, and J. L. Planchet. 2016. "A model to quantify the resilience of mass railway transportation systems." Reliab. Eng. Syst. Saf. 153 (Sep): 1-14. https://doi.org/10 .1016/j.ress.2016.03.015.
Attoh-Okine, N. O., A. T. Cooper, and S. Mensah. 2009. "Formulation of resilience index of urban infrastructure using belief functions." Syst. $J$. 3 (2): 147-153. https://doi.org/10.1109/JSYST.2009.2019148.

Baylis, J., G. S. Gerstell, B. Scott, M. E. Grayson, C. Lau, and J. Nicholson. 2015. "Transportation sector resilience." Accessed May 5, 2017. https:// www.dhs.gov/sites/default/files/publications/niac-transportation-resilience -final-report-07-10-15-508.pdf.

Blake, E. S., E. N. Rappaport, and C. W. Landsea. 2007. The deadliest, costliest, and most intense United States tropical cyclones from 1851 to 2006 (and other frequently requested hurricane facts). Miami: National Oceanic and Atmospheric Administration.

Bocchini, P., and D. M. Frangopol. 2010. "Optimal resilience-and costbased postdisaster intervention prioritization for bridges along a highway segment." J. Bridge Eng. 17 (1): 117-129. https://doi.org/10.1061 /(ASCE)BE.1943-5592.0000201.

Bocchini, P., D. M. Frangopol, T. Ummenhofer, and T. Zinke. 2013. "Resilience and sustainability of civil infrastructure: Toward a unified approach." J. Infrastruct. Syst. 20 (2): 04014004. https://doi.org/10 .1061/(ASCE)IS.1943-555X.0000177.

Briguglio, L., G. Cordina, N. Farrugia, and S. Vella. 2009. "Economic vulnerability and resilience: Concepts and measurements." Oxford Dev. Stud. 37 (3): 229-247. https://doi.org/10.1080/13600810903089893.

Bruneau, M., S. E. Chang, R. T. Eguchi, G. C. Lee, T. D. O'Rourke, A. M. Reinhorn, M. Shinozuka, K. Tierney, W. A. Wallace, and D. von Winterfeldt. 2003. "A framework to quantitatively assess and enhance the seismic resilience of communities." Earthquake Spectra 19 (4): 733-752. https://doi.org/10.1193/1.1623497.

Burns, S., and J. Brett. 2017. "First commute for repaired I-85 bridge." The Atlanta Journal-Constitution. Accessed June 20, 2017. https://www.ajc.com/news/traffic/first-commute-for-repaired-bridge /chch5kVAYPh505Xbrnqg9H/.

Cox, A., F. Prager, and A. Rose. 2011. "Transportation security and the role of resilience: A foundation for operational metrics." Transp. Policy 18 (2): 307-317. https://doi.org/10.1016/j.tranpol.2010.09.004.

Dalziell, E., and A. Nicholson. 2001. "Risk and impact of natural hazards on a road network." J. Transp. Eng. 127 (2): 159-166. https://doi.org/10 .1061/(ASCE)0733-947x(2001)127:2(159).

Daskin, M. S., and Y. Sheffi. 1985. Urban transportation networks: Equilibrium analysis with mathematical programming methods. Englewood Cliffs, NJ: Prentice Hall.

Dong, Y., D. M. Frangopol, and D. Saydam. 2013. "Time-variant sustainability assessment of seismically vulnerable bridges subjected to multiple hazards." Earthquake Eng. Struct. Dyn. 42 (10): 1451-1467. https:// doi.org/10.1002/eqe.2281.

Donovan, B., and D. B. Work. 2017. "Empirically quantifying city-scale transportation system resilience to extreme events." Transp. Res. Part C Emerging Technol. 79 (Jun): 333-346. https://doi.org/10.1016/j.trc .2017.03.002.

Estoque, R. C., and Y. Murayama. 2014. "Social-ecological status index: A preliminary study of its structural composition and application." Ecol. Indic. 43 (Aug): 183-194. https://doi.org/10.1016/j.ecolind.2014 .02 .031 . 
Faturechi, R., and E. Miller-Hooks. 2014a. "Measuring the performance of transportation infrastructure systems in disasters: A comprehensive review." J. Infrastruct. Syst. 21 (1): 04014025. https://doi.org/10.1061 /(ASCE)is.1943-555x.0000212.

Faturechi, R., and E. Miller-Hooks. 2014b. "Travel time resilience of roadway networks under disaster." Transp. Res. Part B Methodol. 70 (Dec): 47-64. https://doi.org/10.1016/j.trb.2014.08.007.

Gannett Fleming. 2010. "Technical report 2: Tampa bay regional planning model (TBRPM) version 7.0 procedural guide." Accessed April 25, 2017. http://www.tbrta.com/downloads/TBRPMv70\%20TR2\%20 -\%20Procedural\%20Guide.pdf.

Gillen, D., and H. Hasheminia. 2016. "Measuring reliability of transportation networks using snapshots of movements in the network-An analytical and empirical study." Transp. Res. Part B Methodol. 93 (Nov): 808-824. https://doi.org/10.1016/j.trb.2016.02.001.

Gunderson, L. H., C. S. Holling, L. Pritchard, and G. D. Peterson. 2002. Resilience of large-scale resource systems, 3-20. Washington, DC: Island Press.

Heaslip, K., W. Louisell, and J. Collura. 2009. "Quantitative evaluation of transportation resiliency for regional networks." In Proc., Transportation Research Board 88th Annual Meeting. Washington, DC: Transportation Research Board.

Hitchcock, W. A., S. Nunez, and S. V. Watson. 2008. Emergency reconstruction of critical transportation infrastructure. UTCA Rep. No. 06211. Tuscaloosa, AL: Univ. Transportation Center for Alabama.

Hopkins, D. C., J. L. Lumsden, and J. A. Norton. 1993. "Lifelines in earthquakes-A case study based on Wellington." Bull. N. Z. Natl. Soc. Earthquake Eng. 26 (2): 208-221.

Hughes, J. F., and K. Healy. 2014. "Measuring the resilience of transport infrastructure." Accessed May 12, 2017. https://www.nzta.govt.nz /assets/resources/research/reports/546/docs/546.pdf.

Ip, W. H., and D. Wang. 2009. "Resilience evaluation approach of transportation networks." In Vol. 2 of Proc., Int. Joint Conf. on Computational Sciences and Optimization, 618-622. New York: IEEE.

Karamlou, A., P. Bocchini, and V. Christou. 2016. "Metrics and algorithm for optimal retrofit strategy of resilient transportation networks." In Maintenance, monitoring, safety, risk and resilience of bridges and bridge networks, 1121-1128. London: Taylor \& Francis.

Maxey, D. 2006. "Emergency repair of the I-10 bridge over Escambia Bay." In Proc., FICE/FDOT Design Conf. Tallahassee, FL: Florida Dept. of Transportation.

Murray-Tuite, P. M. 2006. "A comparison of transportation network resilience under simulated system optimum and user equilibrium conditions." In Proc., 38th Winter Simulation Conf., 1398-1405. New York: IEEE.

Nagurney, A., and Q. Qiang. 2007. "A network efficiency measure for congested networks." EPL (Europhys. Lett.) 79 (3): 38005.

National Hurricane Center. 2016. "Total number of major hurricane strikes by counties/parishes/boroughs, 1900-2010.” Accessed May 15, 2017. https://www.nhc.noaa.gov/climo/images/strikes_egulf_mjr_11.jpg.

Noll, J. 2017. "I-85 collapse, day 2: 12 hours later bridge still smoldering: Traffic challenges commuters." Accessed July 20, 2017. http:// www.11alive.com/article/traffic/i-85-collapse/i-85-collapse-day-2-12 -hours-later-bridge-still-smoldering-traffic-challenges-commuters/85 $-427149901$.

Omer, M., A. Mostashari, and R. Nilchiani. 2011. "Measuring the resiliency of the Manhattan points of entry in the face of severe disruption." Am. J. Eng. Appl. Sci. 4 (1): 153. https://doi.org/10.3844/ajeassp.2011 .153.161.

Omer, M., A. Mostashari, and R. Nilchiani. 2013. "Assessing resilience in a regional road-based transportation network." Int. J. Ind. Syst. Eng. 13 (4): 389-408. https://doi.org/10.1504/ijise.2013.052605.
Padgett, J., R. DesRoches, B. Nielson, M. Yashinsky, O. S. Kwon, N. Burdette, and E. Tavera. 2008. "Bridge damage and repair costs from Hurricane Katrina.” J. Bridge Eng. 13 (1): 6-14. https://doi.org/10.1061 /(ASCE)1084-0702(2008)13:1(6).

Padgett, J. E., A. Spiller, and C. Arnold. 2012. "Statistical analysis of coastal bridge vulnerability based on empirical evidence from Hurricane Katrina.” Struct. Infrastruct. Eng. 8 (6): 595-605. https://doi .org/10.1080/15732470902855343.

Reggiani, A. 2013. "Network resilience for transport security: Some methodological considerations." Transp. Policy 28 (Jul): 63-68. https://doi .org/10.1016/j.tranpol.2012.09.007.

Scott, M. S., and D. K. Maddox. 2001. "Speeding in residential areas." Accessed January 15, 2018. http://citeseerx.ist.psu.edu/viewdoc /download?doi=10.1.1.505.8649\&rep=rep1\&type=pdf.

Serulle, N., K. Heaslip, B. Brady, W. Louisell, and J. Collura. 2011. "Resiliency of transportation network of Santo Domingo, Dominican Republic: Case study." Transp. Res. Rec. 2234: 22-30. https://doi org/10.3141/2234-03.

Sobanjo, J. O., and P. D. Thompson. 2013. "Development of risk models for Florida's bridge management system." Accessed May 12, 2017. http://www.fdot.gov/research/Completed_Proj/Summary_MNT/FDOT -BDK83-977-11-rpt.pdf.

Stearns, M., and J. E. Padgett. 2011. "Impact of 2008 Hurricane Ike on bridge infrastructure in the Houston/Galveston region.” J. Perform. Constr. Facil. 26 (4): 441-452. https://doi.org/10.1061/(ASCE)CF .1943-5509.0000213.

Ta, C., A. Goodchild, and K. Pitera. 2009. "Structuring a definition of resilience for the freight transportation system." Transp. Res. Rec. 2097: 19-25. https://doi.org/10.3141/2097-03.

Talbot, J. 2005. "Repairing Florida's Escambia Bay bridge." Accessed June 15, 2017. https://web.archive.org/web/20060127004702/http:// www.acppubs.com/article/CA511040.html.

Tamvakis, P., and Y. Xenidis. 2012. "Resilience in transportation systems." Procedia Social Behav. Sci. 48: 3441-3450. https://doi.org/10.1016/j .sbspro.2012.06.1308.

Tanasić, N., V. Ilić, and R. Hajdin. 2013. "Vulnerability assessment of bridges exposed to scour." Transp. Res. Rec. 2360: 36-44. https://doi .org/10.3141/2360-05.

Transportation Research Board. 1985. Highway capacity manual. 2nd ed. TRB Special Rep. No. 209. Washington, DC: National Research Council.

Twumasi-Boakye, R., and J. O. Sobanjo. 2017. "Evaluation of transportation user costs based on simulated regional network models." Transp. Res. Rec. 2612: 121-131. https://doi.org/10.3141/2612-14.

Twumasi-Boakye, R., J. O. Sobanjo, S. K. Inkoom, and E. E. Ozguven. 2018. "Senior community resilience with a focus on critical transportation infrastructures: An accessibility-based approach to healthcare." In Proc., Transportation Research Board 97th Annual Meeting. Washington, DC: Transportation Research Board.

Vugrin, E. D., D. E. Warren, and M. A. Ehlen. 2011. "A resilience assessment framework for infrastructure and economic systems: Quantitative and qualitative resilience analysis of petrochemical supply chains to a hurricane." Process Saf. Prog. 30 (3): 280-290. https://doi.org/10.1002 /prs. 10437.

Xie, K., K. Ozbay, and H. Yang. 2015. "Spatial analysis of highway incident durations in the context of Hurricane Sandy." Accid. Anal. Prev. 74 (Jan): 77-86. https://doi.org/10.1016/j.aap.2014.10.015.

Zhang, L., Z. Huang, Y. Wen, and M. Jin. 2009. The framework for calculating the measure of resilience for intermodal transportation systems: State study 220. Rep. No. FHWA/MS-DOT-RD-10-220A. Jackson, MS: Mississippi Dept. of Transportation.

Zobel, C. W. 2010. "Comparative visualization of predicted disaster resilience.” In Proc., 7th Int. ISCRAM Conf., Seattle, 1-5. 